\title{
The determinants of health among the population aged 50 and over: evidence from Croatia
}

ŠIME SMOLIĆ, Ph.D.*

\section{Article**}

JEL: I12, I18

https://doi.org.10.3326/pse.41.1.9

\footnotetext{
* The author would like to thank the participants of the conference "Public sector economics" and two anonymous referees for their valuable comments and suggestions. The work on this paper has been partially supported by the Croatian Science Foundation under the project 7031.

${ }^{* *}$ Received: October 19, 2016

Accepted: December 29, 2016
}

A previous version of this paper was presented at the conference Public Sector Economics organized by the Institute of Public Finance and Friedrich-Ebert-Stiftung in Zagreb on October 14-15, 2016.

Šime SMOLIĆ

Faculty of Economics and Business, University of Zagreb, Trg J. F. Kennedyja 6, 10000 Zagreb, Croatia e-mail: ssmolic@efzg.hr ODCID iD: 0000-0003-0920-8046 


\section{Abstract}

The aim of this paper is to explore the association between demographic, socioeconomic and physical health variables and self-assessed health (SAH) of people aged 50 years and over in Croatia. Cross-sectional data was collected in 2012 in the survey "The Economics of Ageing in Croatia" that was based on the SHARE (Survey of Health Ageing and Retirement in Europe) study. Altogether 761 individuals aged 50 and over were included in the working sample that has been used in statistical analysis. Data were analysed in an ordered logistic regression model. The results show that females were more likely to report a higher category of SAH than males. Higher educational level was a statistically significant predictor of higher SAH, when controlled for other variables. This study, unlike other studies in Croatia, introduces a set of physical health variables as the determinants of health. Our results suggest that people aged 50 and over with fewer limitations, health related symptoms and diagnosed chronic conditions were more likely to report higher levels of SAH. These findings could be beneficial to policymakers in their efforts to improve health among elderly in Croatia.

Keywords: self-assessed health (SAH), Croatia, SHARE, population ageing, health determinants

\section{INTRODUCTION}

Population health status and health care systems have always been of strategic importance for a country. Health care is a key determinant in maintaining good health, which in turn affects a country's productivity and the level of social wellbeing. Western countries have experienced a significant increase in total health care expenditures since the 1980s, and its share in GDP will continue to rise in the future. This increase is mainly spurred by population ageing (Harper, 2006; Dormont, Grignon and Huber, 2006), and improvements in medical technology (Okunade and Murthy, 2002; Bodenheimer, 2005). Health care expenditure trends could become a great challenge for the public health care systems in developed countries, seriously threatening their sustainability (Newhouse, 1992; Follette and Sheiner, 2005; Stuckler, Basu and McKee, 2013).

The Croatian health care system is built on the principle that virtually all legal residents have equal access to health care. It is a mixed system financed from both public and private sources. The majority of the funds to finance health care provision is pooled via compulsory health insurance contributions. Co-payments are applied to certain statutory services, and these have either to be paid out-of-pocket (OOP) or covered by complementary health insurance (Džakula et al., 2014). There is also voluntary supplementary health insurance for higher standards of health care services (Vončina et al., 2006). The World Health Organisation (WHO) (2016a) estimated that the total Croatian health expenditure was $7.8 \%$ of GDP, which is approximately 1,650 PPP\$ per capita. When compared to other European Union countries Croatia is among countries with the lowest health expenditure per capita just ahead Bulgaria, Romania and Latvia. Private expenditures are 
mainly in the form of OOPs, but in 2014 they amounted only to $18 \%$ of total spending on health in Croatia (WHO, 2016a).

If we look at the general health status of the Croatian population, we can see it continued to improve during $21^{\text {st }}$ century at a relatively moderate pace. Life expectancy at birth rose from 73 years in 2000 to 78 years in 2014. The increase was larger for males (from 69.1 to 74.8 years) than for females (76.7 to 81.1 years) (WHO, 2016a). At the same time healthy life expectancy (HALE) at birth reached 69.4 years in 2015 for both sexes, an increase of 3 years from 2000 (WHO, 2016b). We can observe a steady increase in the gap between HALE and life expectancy at birth, which indicates that people in Croatia spend on average more years in poor health. Indeed, the high prevalence of cardiovascular diseases and increase of cancer incidence rates could be the reasons for a decrease in health quality and consequently in healthy life expectancy. Most recent data from 2014 show that ischaemic heart and cerebrovascular diseases were the leading cause of $35 \%$ of deaths in the general population and nearly $40 \%$ of deaths among the population aged 65 and over, followed by malignant neoplasms in second place (CNIPH, 2016). Therefore, we can state that the efficiency of the Croatian health care system should be questioned since health care systems should strive to improve health status, compress morbidity and disability, especially in advanced ages, and thus extend HALE.

Recent empirical research use self-assessed health status as a common measure of health and health system performance. In order to improve our understanding of the general health of older Croatian citizens we explore several determinants of the most important measure of health at an individual level, i.e. self-assessed health status (SAH). SAH is easy to measure, and is widely used to measure health in many international studies, e.g. European Values Study (EVS), European Community Household Panel (ECHP) or the Survey of Health Ageing and Retirement in Europe (SHARE). In general respondents are asked to assess their own health status using a four or five-point scale, either from "excellent" to "poor" (US version of SAH) or from "very good" to "very bad" (European version of SAH) (Idler and Benyamini, 1997; Jürges, Avendano and Mackenbach, 2008). SAH is considered to be the most feasible, inclusive and informative measure of health status (Idler and Benyamini, 1997; Jylhä, 2009). In addition, SAH has proven to be a strong and valid predictor of future mortality and morbidity or even disability (see e.g., Bailis, Segall and Chipperfield, 2003; Franks, Gold and Fiscella, 2003; Nicholson et al., 2005; McFadden et al., 2009; Kaplan et al., 1996; Dominick et al., 2002).

In Croatia, only few studies cover the topic of SAH determinants and further research as from the international studies should be encouraged. A study done by Čipin and Smolić (2013a) explored the demographic and economic determinants of SAH in Croatia from four different cross-sectional data sets. Their findings suggest that age is the most important determinant of SAH in Croatia, followed by educational level. The effects of household income and employment status, when combined with other variables, were ambiguous and even statistically insignifi- 
cant in some data sets. Other research papers explored the association between lower income and educational level and individual health status (Šućur and Zrinšćak, 2007) or financial resources and health of unemployed people in Croatia (Galić, Maslić Seršić and Šverko, 2006). Unlike the previously mentioned research on health determinants in Croatia, this study emphasizes variables of physical health, e.g. (instrumental) activities of daily living, chronic health conditions and physical limitations, and exposure to risk behaviors like tobacco use and alcohol consumption. Indeed, physical health measures were significantly associated with SAH among persons aged 50 and over. Respondents who reported fewer (I)ADL limitations, chronic health conditions and distressing symptoms were more likely to report higher category of SAH. In addition, we found statistically significant association between the variables "gender", "educational level", "household income", "help received" and SAH.

The rest of this paper is organized as follows: in section 2 of the literature review SAH is explained and linked with key determinants of health. In section 3 we describe the methodology and data. Following in section 4 we present the results of ordered logistic regression and in section 5 we discuss policy implications, study limitations and suggestions for future studies of SAH in Croatia.

\section{LITERATURE REVIEW}

\subsection{SELF-ASSESSED HEALTH}

In a detailed review of twenty-seven studies Idler and Benyamini (1997) detected SAH as an independent predictor of mortality. Many other studies since the $1980 \mathrm{~s}$ revealed this consistency in conclusions about SAH. The SAH measure is simple, inexpensive, widely used, reliable and a predictive indicator of mortality even when many other determinants are controlled for (Kaplan and Camacho, 1983; Idler and Angel, 1990; Idler and Kasl, 1991; Kaplan et al., 1996; Reile and Leinsalu, 2013; Schnittker and Bacak, 2014; Meng and D'Arcy, 2016). SAH is easy to measure (Bobak et al., 2000), predicts longevity (Mossey and Shapiro, 1982) and is a powerful predictor of future health and health services utilization (Jylhä, 2009). In the longitudinal framework, Bailis, Segall and Chipperfield (2003) have found that present SAH significantly predicted a respondent's future SAH. Nevertheless, we still poorly understand the association of SAH with mortality because there is no single, universal agreement upon a definition or direct measure of "health" or "health status" (Jylhä, 2009:309). However, the lack of its definition is viewed, in part, as the strength of self-rated health (Schnittker and Bacak, 2014). Idler and Angel (1990) argued about the inability of self-reports unambiguously to control for objective health status. They say that assessing the medical significance of SAH is difficult, while Jylhä (2009) questions the comparability of SAH distributions across cultural groups and distant age groups. Idler and Banyamini (1997) conclude that cross-cultural differences affect the consistency of international studies of SAH, and Jylhä (2009) proposed the use of qualitative approaches in studying how respondents reason about their health, and pointed out the role of experience and bodily sensations and biomarkers to better understand a biological basis of SAH. 
We find a similar conclusion in the study of Lindeboon and van Doorslaer (2004: 1084) where, e.g. age, sex, education, language and personal experience of illness can influence the answers on SAH in different sub-groups of the population even though they have the same level of "true" health. Desesquelles, Egidi and Salvatore (2009) noticed the following problems with the comparability of SAH data for people in France and Italy: different wording of SAH questions, the order in which response categories were listed in questionnaires, and the different time the surveys were carried out. In addition, Jürges, Avendano and Mackenbach (2008: 779) conclude that "differences in the wording of response categories could lead to bias in comparisons of SAH between countries". Peersman et al. (2012) revealed the importance of another approach in understanding what a global SAH item measures by asking people to elaborate their assessment of health. Several studies (see e.g., Crossley and Kennedy, 2002; Zajacova and Beam Dowd, 2011) also found that respondents tend to give different answers when asked standard SAH question twice or on two different occasions.

Idler and Banyamini (1997) proposed more detailed investigation of this issue which is related closely with the survey instrument and survey methods (e.g., responses to the SAH question could be affected by their context in the survey instrument). The differences in responses can be quite significant, e.g. $28 \%$ of respondents changed their answer after a set of health questions in the study of Crossley and Kennedy (2002), and nearly 40\% between two interviews one month apart (Zajacova and Beam Dowd, 2011). To conclude this part, we have to mention studies reporting SAH as nonsignificant or a not so strong predictor of mortality. They usually include only older (old and old-old) people in the samples (Idler and Angel, 1990; Banyamini et al., 2003) or study only certain populations (Idler and Banyamini, 1997, call these "special populations"), e.g. African Americans (Ferraro and Kelley-Moore, 2001).

\subsection{THE DETERMINANTS OF SELF-ASSESSED HEALTH}

There is a strong commitment of many cross-sectional and longitudinal studies to exploring important determinants of SAH. Many researchers since the 1980s have endeavoured to understand the complexity of health assessment influenced by different socio-economic, demographic, cultural, psychological or political factors. Idler and Banyamini (1997) detected a wide range of SAH determinants in studies from all over the world. Among them age and gender, variables of socioeconomic status, e.g. educational level and income, measures of chronic conditions and functioning, health practice risk factors (smoking and alcohol consumption), and measures of social networks and life satisfaction were the most common.

We present major findings of national and cross-country studies of SAH determinants in the following part of the paper. In the study for seven post-communist countries (Russia, Estonia, Lithuania, Latvia, Hungary, Poland and Czech Republic), Bobak et al. (2000) found a strong association between educational level and material deprivation and $\mathrm{SAH}$, i.e higher educational levels and lack of material 
deprivation were associated with higher category of SAH. Similar analysis done in Russia concluded that education, marital status, ability to rely on informal care or absence of informal social networks affect SAH (Bobak et al., 1998). In order to investigate the SAH in Estonia, Reile and Leinsalu (2013) included age, gender, ethnicity, educational level, and income, measures of physical health (chronic and long-term illnesses) and psychological health (depression) as predictors. The strongest associations were found for indicators of physical health, i.e. Estonians without any chronic illnesses or restrictions on their daily activities reported better health, ceteris paribus. A longitudinal study in Canada revealed the effects of determinants like gender, age, place of residence, education, marital status, etc. on SAH status change. The most important findings however were related to daily functioning and number of chronic illnesses that were consistently associated with SAH at each wave of the study (Meng and D'Arcy, 2016).

Pirani and Salvini (2012) focused on SAH of Italian population 65 and over by employing age, gender, diagnosed chronic illnesses, socioeconomic status, measures of lifestyle, family structure and social network. They found a slightly lower effect of education on SAH than similar studies, and they were discreet in conclusions about the effects of the economic situation on SAH. However, they stress the strong association between poor health and inadequate social networks (e.g., spouses, relatives or friends) among elderly Italians. From the seven-country study of Mackenbach et al. (2005) we realize that higher household income is associated with better SAH among men and women. This result has been confirmed in Estonia (Reile and Leisalu, 2013), Canada (Meng and D’Arcy, 2016), Croatia (Šućur and Zrinšćak, 2007).

Marital status is very often a significant predictor of SAH because the availability of spousal support is considered an important determinant of health outcomes (Dominick et al., 2002). Conclusions on the association of this variable and SAH are not homogeneous however. They still range from being complex, especially in the multinational studies (e.g., Huijts, Monden and Kraaykamp, 2010; Desesquelles, Egidi and Salvatore, 2009), notably nonsignificant for older age groups (Bobak et al., 1998; Nicholson et al., 2005), and significant for men and women and people aged 65 and over (e.g., Leinsalu, 2002; Meng and D'Arcy, 2016). A report on the elderly Spanish population found age, chronic conditions and functional status to be the main determinants of SAH (Damian et al., 1999). Peersman et al. (2012) confirmed that physical health problems are the dominant determinant among the respondents who were rating their health, but other reasons beyond physical functioning have been detected too, e.g. prior health experience or educational background. Prior health experience and socioeconomic situation over the life course have been detected as very important determinants of SAH in one study of Russians aged 50 and over made by Nicholson et al. (2005).

In Croatia, we found only a few studies where the determinants of SAH have been analysed. Šućur and Zrinšćak (2007) examined the differences in SAH and access 
to health care, controlling for different income groups, urbanization level, and regional distribution in Croatia and European Union countries. In addition, Galić, Maslić Seršić and Šverko (2006) examined the financial situation and health of unemployed individuals, while Čipin and Smolić (2013a) analyse four cross-sectional data sets available in Croatia (ESS, EVS and ISSP) to explore the extent to which individual health is related to demographic and socio-economic determinants. More work on SAH determinants in Croatia is thus required. Currently there are only cross-sectional frameworks in use, but in the future, there will be longitudinal data sets available from studies like SHARE.

\section{DATA AND METHODS}

The data used in this paper come from the survey "The Economics of Ageing in Croatia" that was based on SHARE questionnaires from waves 1 and 2. SHARE is a unique longitudinal database of micro data on the health, socio-economic status and social and family networks of respondents aged 50 and over covering most of the European Union, Switzerland and Israel (Börsch-Supan et al., 2013). Croatia formally joined the SHARE study for wave 6 in 2014. Respondents in this survey were all members of randomly selected households present in 221 settlements in Croatia, aged 50 and over at the time of the interview (i.e., they were born in 1962 or before), and their partners irrespective of their age. The sample was designed as a two-level random sample, where the first level of the selection was the selection of sampling points with corresponding addresses of persons aged 50 and over in all Croatian counties. Sampling points were settlements stratified by size (population aged 50 and over) in four categories: 30,000 and over, 5,00029,999, 500 - 4,999 and 499 or less. By simple random selection from each stratum, we have selected as many addresses that proportionally correspond to the size of the individual strata in total population.

Each respondent had a 70-minute face-to-face interview (CAPI) with our interviewers. Interviews were conducted from July to December 2012. Most respondents $(86 \%)$ filled in an additional short drop-off questionnaire, which they returned to the interviewer or mailed to the agency shortly after the interview. In total, 1,180 respondents aged 50 and over were interviewed in 855 households. The response rate of sampled households was 53\% (Čipin and Smolić, 2013b). For the purpose of this paper, we have excluded partners who were born in 1963 or later. Complete data on all variables were available for 761 respondents. In the next steps, the determinants found to be associated with SAH were included in the analysis. We use ordered logistic regression to determine the association between $\mathrm{SAH}$, the outcome variable, and already theoretically established a set of socioeconomic, health status and demographic variables. Ordered categorical variables like SAH, measured on an ordinal 5-point Likert type scale are appropriate for ordered regression models (see e.g., Agresti, 2002; Liu and Agresti, 2005; Long and Freese, 2006). In addition, the SAH scale has been modified so that higher numbers correspond to better health. The data set contains a single-item measure of $\mathrm{SAH}$, which assessed individual health perception measured on an ordinal 
5-point scale. Respondents were asked this question: "Would you say your health is... very good, good, fair, bad or very bad?"

Age was measured in years, and categorized into two groups: "50-64" and "65 and over". Educational level is presented at three levels: primary education or below (ISCED 0-2), secondary level of education (ISCED 3-4) and tertiary education (ISCED 5-6) as the reference category. We categorized marital status in four groups while the reference group is "Married". In addition, the variable of social support was included that indicates if the respondent received help from outside the household or from a helper in the household. To capture the lifestyle of respondents, we use BMI equal or greater than 30 indicating obese respondents, share of smokers, ex-smokers and non-smokers, and lastly the share of those who had one or more drinks per week. Asking respondents to answer whether they were suffering from, e.g. back or joint pain, angina or chest pain, breathlessness, sleeping problems, etc. we found out more about symptoms, which is another important determinant of SAH.

The economic situation is described by employment status of respondents containing five categories. Moreover, respondents in this survey (financial respondents) were asked to think of household's total monthly income. Household financial situation was assessed using a question: "Thinking of your household's total monthly income, would you say that your household is able to make ends meet..." with the answer options "with great difficulty", "with some difficulty", "fairly easily" and "easily". Answer options were categorized in two "some or great difficulty" and "no difficulty". We did not obtain precise data about income on an individual level, and only the reported financial situation of households was included our model.

\section{RESULTS AND DISCUSSION}

Table 1 represents the distribution of outcome and predictor variables. On average $38.4 \%$ of respondents reported their health as "Fair", and around one out of three assessed their health as good or very good. However, almost every fifth man and every third woman reported a bad or very bad category of SAH. A descriptive analysis of the sample revealed that the share of females is somewhat higher, while the majority of the respondents have completed secondary education. The proportion of married respondents in the sample was very high, and one out of four individuals aged 50 and over is widowed, mainly females (37.4\% of females vs. $8.4 \%$ of males). Every fourth respondent lived alone, one third of them with a spouse or partner only and the rest of the sample respondents with others only (e.g., children, other relatives and non-relatives). Around 35\% of respondents received a number of different types of help (e.g., care, help with practical tasks and administrative tasks) from either outside or inside the household. 


\section{TABLE 1}

Socio-economic, health and demographic variables, and SAH (percentages) among individuals aged 50 and over in Croatia from "The Economics of Ageing in Croatia” survey in 2012

Variable

SAH

Age $^{\mathrm{a}}$

Gender

Educational level

Marital status

$\longrightarrow$ Div

Help received

Living with

Smoking

Drinking

Conditions

Symptoms

(I)ADL

\section{Very bad}

Bad

Fair

Good

Very good

50-65

65 and over

Male

Female

Primary or below

Secondary

Tertiary

Married

Widowed

Never married

Divorced/separated

No help received

Help from household member(s)

Help outside household

Living alone

Living with spouse/partner

Living with others

Less than 30

Equal to or greater than 30 (obese)

Current smoker

Ex-smoker

Non smoker

At least once per week

No diagnosed condition

One or two conditions

Three or more conditions

No symptom

One or two symptoms

Three or more symptoms

No (I)ADL limitation

One or two(I)ADL limitations

Three or more (I)ADL limitations

Employed

Unemployed

Retired

At home

Other

Some or great difficulty

No difficulty
Weighted \%

6.67

20.74

38.42

22.35

11.82

50.05

49.95

40.88

59.12

34.75

45.84

19.41

62.91

25.52

5.47

6.10

65.69

23.12

11.18

23.07

32.95

43.98

71.82

28.18

23.69

23.75

52.26

34.06

26.15

48.95

24.90

25.16

43.46

30.38

56.45

26.24

17.31

16.37

9.30

60.30

12.65

1.38

78.50

21.50

Household financial situation $^{c}$

$\overline{{ }^{a}}$ Mean age $=65.45$ years. ${ }^{b}$ Categories: underweight $=B M I \leq 18.49 ;$ normal weight $=B M I$ 18.50-24.99; overweight $=B M I$ 25.00-29.99; obese $=B M I \geq 30.00 .{ }^{\circ}$ Reported income at the household level only.

Source: Author calculations. 
TABle 2

Odds ratios (OR) with p-values and 95\% confidence intervals (CI) from the ordered logistic regression of the self-assessed health (SAH) of men and woman aged 50 and over in Croatia (N=761); "The Economics of Ageing in Croatia" survey

\begin{tabular}{|c|c|c|c|}
\hline \multirow{3}{*}{$\begin{array}{l}\text { Age (50-64) } \\
65 \text { and over }\end{array}$} & \multirow[t]{2}{*}{ OR } & \multicolumn{2}{|c|}{$95 \%$ CI } \\
\hline & & & \\
\hline & 0.82 & 0.57 & 1.19 \\
\hline \multicolumn{4}{|l|}{ Gender (Male) } \\
\hline Female & $1.61^{* *}$ & 1.15 & 2.26 \\
\hline \multicolumn{4}{|l|}{ Educational level (Tertiary) } \\
\hline Primary or below & $0.39 * * *$ & 0.25 & 0.62 \\
\hline Secondary & $0.54 * * *$ & 0.37 & 0.78 \\
\hline \multicolumn{4}{|l|}{ Marital status (Married) } \\
\hline Widowed & 0.89 & 0.54 & 1.48 \\
\hline Never married & 0.70 & 0.33 & 1.49 \\
\hline Separated/divorced & 0.60 & 0.31 & 1.17 \\
\hline \multicolumn{4}{|l|}{ Help received (No help received) } \\
\hline Help from household member(s) & $0.51 * *$ & 0.32 & 0.83 \\
\hline Help outside household & 0.73 & 0.51 & 1.03 \\
\hline \multicolumn{4}{|l|}{ Living with (Living alone) } \\
\hline Living with spouse/partner & 1.30 & 0.73 & 2.34 \\
\hline Living with others & 1.32 & 0.82 & 2.14 \\
\hline BMI equal to or greater than 30 & 1.04 & 0.76 & 1.42 \\
\hline \multicolumn{4}{|l|}{ Smoke (Never smoker) } \\
\hline Ex-smoker & 1.13 & 0.79 & 1.62 \\
\hline Current smoker & 1.03 & 0.72 & 1.49 \\
\hline Drink & 0.84 & 0.61 & 1.16 \\
\hline \multicolumn{4}{|l|}{ Conditions (Three or more) } \\
\hline No diagnosed condition & $3.86^{* * *}$ & 2.42 & 6.15 \\
\hline One or two conditions & $1.78 * *$ & 1.23 & 2.58 \\
\hline \multicolumn{4}{|l|}{ Symptoms (Three or more) } \\
\hline No symptom & $6.21 * * *$ & 3.84 & 10.05 \\
\hline One or two symptoms & $2.05 * * *$ & 1.41 & 2.99 \\
\hline \multicolumn{4}{|l|}{ (I)ADL (Three or more) } \\
\hline No limitation & $7.46^{* * *}$ & 4.51 & 12.36 \\
\hline One or two limitations & $3.65^{* * *}$ & 2.28 & 5.86 \\
\hline \multicolumn{4}{|l|}{ Employment status (Employed) } \\
\hline Unemployed & 0.77 & 0.43 & 1.39 \\
\hline Retired & 0.84 & 0.53 & 1.33 \\
\hline At home & 0.83 & 0.44 & 1.58 \\
\hline Other & 0.33 & 0.09 & 1.16 \\
\hline \multicolumn{4}{|l|}{$\begin{array}{l}\text { Household financial situation } \\
\text { (Some or great difficulty) }\end{array}$} \\
\hline No difficulty & $2.07 * * *$ & 1.46 & 2.93 \\
\hline
\end{tabular}

Note: $* p<0.05 ; * * p<0.01 ; * * * p<0.001$. Reference category is in the brackets. 
A very small proportion of respondents reported being underweight, but more than seven out of ten fit in the overweight and obese groups. One out of four respondents smoked every day while $24 \%$ of them stopped smoking. More than $34 \%$ respondents had at least one drink per week whereas $15 \%$ have been drinking every day in the last six months. From table 1 we notice that almost every second respondent has been diagnosed with, or currently has, one or two health problems (conditions), e.g. high blood pressure or hypertension, high blood cholesterol, diabetes, osteoporosis, etc.

Only one out of four respondents did not report problems with the symptoms presented on the showcard during interviews. Problems with activities of daily living (ADL), e.g. dressing, eating, bathing, and instrumental activities of daily living (IADL), e.g. cooking, shopping, etc. were observed for almost every second respondent aged 50 and over in the sample. As expected, employment rate among elderly individuals was low. Nonetheless, one out of three individuals aged 50 and over in the working contingent age group was employed, and another $16 \%$ of them were looking for a job. We noticed a bulk of households (almost 80\%) having at least some difficulty in making ends meet in a typical month.

As mentioned earlier, 761 cases were included in the working sample, and the SAH scale has been modified so that higher numbers correspond to better health. The parallel regression assumption in the ordered logistic model has not been violated, and the results are displayed as proportional odds ratios in table 2. Inferential findings are explained separately by each or a group of the SAH determinants.

\subsection{GENDER}

We found a statistically significant association between gender and SAH. Men aged 50 and over were less likely to report higher categories of SAH than women were, after controlling for other variables in the model. Conclusions on gender differences with respect to $\mathrm{SAH}$ from previous research are not clear enough (McDonough and Walters, 2001). In many cases, the determinants of SAH are explored separately for men and women. Gender gap in SAH is observed in the general population, e.g. from the EU-SILC data in 2014 for all EU member states. For the Croatian population aged 16 years and over, men were more likely to rate their health as very good or good, whereas women tended to rate their health lower. In addition, healthy life expectancy based on self-perceived health at the age of 50 was 17.8 years for males and 19.2 years for females in 2014 (Eurostat, 2016a). Another striking indicator available from the EU-SILC is "self-perceived long-standing limitations in usual activities due to a health problem". Among the population aged 65 and over $27.7 \%$ of males and $30.5 \%$ of females reported severe levels of activity limitation due to health problems in 2015. The proportions of men and women aged 65 and over who reported some or severe level of activity limitation were $68.5 \%$ and $75.9 \%$, respectively (Eurostat, 2016b). Čipin and Smolić (2013a) used four different data sets to explore SAH determinants in Croatia, and did not find statistically significant gender differences in $\mathrm{SAH}$ in the European 
Social Survey data sets. Benyamini, Leventhal and Leventhal (2000) argue that men's SAH judgments reflect mainly serious, life threatening, whereas women's $\mathrm{SAH}$ judgments reflect both life-threatening and non-life-threatening diseases.

Furthermore, while reporting their SAH respondents' perceptions of health status seem to be holistic, e.g. they also include information on medical status. Also, men and women in different social positions evaluate such information differently with different reference groups providing different social comparisons (Idler and Benyamini, 1997). On the other hand, a follow-up study of sociodemographic factors of SAH and mortality in the US show that women report lower health status but exhibit lower mortality (Franks, Gold and Fiscella, 2003). Poor health ratings among male respondents could indicate prevalence of more serious health conditions, but their poor ratings are more predictive of mortality than women's poor rating (Idler and Benyamini, 1997). After all, we should not forget that SAH could be affected by respondents' subjective perception, their social and cultural background as well as by their previous health experience.

\subsection{EDUCATIONAL LEVEL}

Educational level proved to be strongly associated with better SAH. Individuals who have completed primary education or lower (e.g., who finished elementary school only or did not complete elementary school) and secondary education, were significantly less likely to report higher category of the SAH than those with tertiary education, controlling for other variables. This finding comes as no surprise, as it was already confirmed in many previous studies. Low educational level is often found to be an important determinant of poor health and systematically higher morbidity and mortality rates (Leinsalu, 2002; Mackenbach, 2006; Beam Dowd and Zajacova, 2007). Education is generally the most basic variable in improving the health of the population. The Grossmans' theory of demand recognized the central role of education implying that better-educated persons tend to be economically more efficient producers of health status (Grossman, 1972).

\subsection{LIVING ARRANGEMENTS AND SUPPORT}

Widowed, non-married and separated/divorced versus married subjects were less likely, but non-significantly, to report a higher SAH category. Huijts and Kraaykamp (2011) proved that the strength of the relationship between marital status and the SAH differs substantially among nations, and that is affected by the national marital status composition. Because of the high proportion of married persons aged 50 and over in Croatia, health selectivity into marriage, i.e. selection of healthy people in the marriage and of unhealthy people into widowhood or divorce (Huijts and Kraaykamp, 2011:284), seems to play a stronger role.

We also analysed the association between household size and the SAH of respondents. Living with spouse/partner only or living with other family members only was positively associated (but statistically non-significant) with better health. Individuals, who were living with spouse/partner only or with others only as com- 
pared to people living alone, were more likely to report a higher category of SAH, ceteris paribus. A variable "help received" is employed to understand who provided the support or a help to respondents. Respondents who have received help from (a) household member(s) were significantly less likely to report a higher category of SAH. A similar finding accounts for a category "help received outside the household"; however, the association between it and SAH was not statistically significant.

\subsection{RISK BEHAVIOURS AND PHYSICAL HEALTH}

Ex-smokers and current smokers had a non-significantly slightly higher likelihood of reporting higher levels of SAH, while drinkers were less likely, and again nonsignificantly, to report higher $\mathrm{SAH}$, holding all the other variables constant. Descriptive analysis showed that functional status deteriorates with age, e.g. almost $70 \%$ of respondents in the 50-64 age group had no limitation (combined ADL and IADL) as compared to $43 \%$ of those aged 65 and over. Moreover, we can see that multi-morbidity is prevalent in older age groups, i.e. one out of three persons aged 65 and over reported being diagnosed with or suffering from three or more illnesses, but only one out of seven respondents reported the same in the youngest age group. Even though previous research in Croatia confirmed that SAH deteriorates with age (e.g., Čipin and Smolić, 2013a) we are not able confirm these findings. When analysing covariates of physical health, i.e. daily functioning, number of chronic conditions and number of symptoms that distress people in their everyday life, we found consistency in association with the SAH. Average odds ratios (OR) ranging from 1.78 to 7.46 indicate a several times higher likelihood of respondents who reported one or two symptoms and no symptom, respectively, versus respondents having three or more symptoms to be in higher category of the subjective health status measure, controlling for the rest of model variables. In addition, people with no diagnosed condition were significantly more likely to report a higher SAH category.

Comparing the categories of (I)ADL limitations, people without any (I)ADL limitation were significantly more likely to report higher categories of the SAH than individuals with at least three (I)ADL limitations. For a better SAH, fewer limitations on physical and instrumental daily functioning and fewer diagnosed chronic conditions proved very important. This conclusion has been confirmed in the study of Meng and D'Arcy (2016) on longitudinal data, for each of three observed waves. Reile and Leinsalu (2013) established it in one Estonian study where those who had limitations in their daily activities were 4.5 times more likely to assess their health as bad or very bad. They conclude that "the SAH scale demonstrates continuity in respect to physical health measures", i.e. association for physical variables was statistically significant across all SAH levels (Reile and Leinsalu, 2013:561). Lima-Costa et al. (2012) investigated the socioeconomic inequalities in health and concluded that physical functioning is a key measure of successful ageing. Similar findings came from the studies in Japan (Sun et al., 2007), France and Italy (Desesquelles, Egidi and Salvatore, 2009), etc. 
In the working sample, about $57 \%$ of respondents who were employed reported very good or good health compared with slightly less than half of those who were not employed. Previous studies confirmed significant association between unemployment and poor SAH (e.g., Giatti, Sandhi and Cibele, 2010; Desesquelles, Egidi and Salvatore, 2009), while financial deprivation could lead to the poor health of unemployed persons (Galić, Maslić Seršić and Šverko, 2006). Unemployed, retired and persons at home were less likely to report better health, but we could not confirm that any category is significantly associated with SAH.

A better household financial situation, i.e. referring to those households that are able to make ends meet with their monthly income easily or fairly easily is significantly associated with better SAH among both men and women. Respondents from the households with no difficulty in making ends meet with their monthly income were 2.1 times more likely to be in a higher category of SAH than individuals living in households that experienced some or great difficulty in making ends meet, controlling for the rest of the model variables. Our findings clearly support previous conclusions that income is an important predictor strongly associated with health among men and women.

\section{CONCLUSION}

Findings in this paper can be considered useful for policymakers within health and social care systems in Croatia. They should foster evidence-based public policy measures that could increase the physical functioning of the older population. Social security is already a large part of government spending in Croatia, and costs of pensions, disability allowances and long-term health care are becoming a great problem. One of the most challenging issues in the next decade will probably be a serious increase in the demand for long-term care services. This will occur because of the higher incidence of chronic disease in the cohorts moving into older ages and morbidity expansion. The negative consequences could be curtailed if a more efficient health care system could reduce morbidity and disability by improving general health of the population and increasing healthy life expectancy. This paper also revealed the positive effects of education on the health of an individual. Policymakers should realize that education is associated with health inequality, and encourage policies for more years of schooling and supporting early childhood education that may have health benefits (Adler and Newman, 2002). Governments should support education institutions and programs, e.g. lifelong learning programs among the elderly especially for "older workers". Finally, following the paper's findings we saw that financial situation could have an important role in an individual's health status. We found that a better financial situation is significantly associated with better health among the population aged 50 and over. A disadvantaged financial situation, which is highlighted among today's older population in Croatia, may have detrimental effects on health status. Nevertheless, the perspectives for the improvement of their current living standards are not so bright, even in the long run. The number of pensioners will con- 
tinue to grow, and combined with inadequate income from pensions, could lead to a further decline in the average health of the elderly.

Like many other studies, this study exhibits several limitations. One of them is the cross-sectional data that are not adequate to explore the causal relationship between education and health, or any other health determinant. Longitudinal data sets are thus necessary to improve our understanding of health and health changes in Croatia. In addition, we excluded other determinants of the SAH in our model that might also help to explain health inequalities. Forthcoming research of the SAH determinants in Croatia, besides the longitudinal data, could include a set of country-specific variables, e.g. exposure to the homeland war of certain populations or address the regional differences in SAH properly. The low response rate (e.g., household response rate of $53 \%$ and individual response rate of $42 \%$ in this survey) could also be an issue. Additional concern arises from the discovery that respondents tended to give different answers when asked standard SAH question twice or on two different occasions, and this is especially the case with older individuals. Lastly, despite the subjective nature of outcome variable and predictors, the results presented in this paper should be considered relevant and reliable estimators of the health status of the elderly in Croatia as well as good predictors of future health care needs.

\section{Disclosure statement}

No potential conflict of interest was reported by the author. 
100
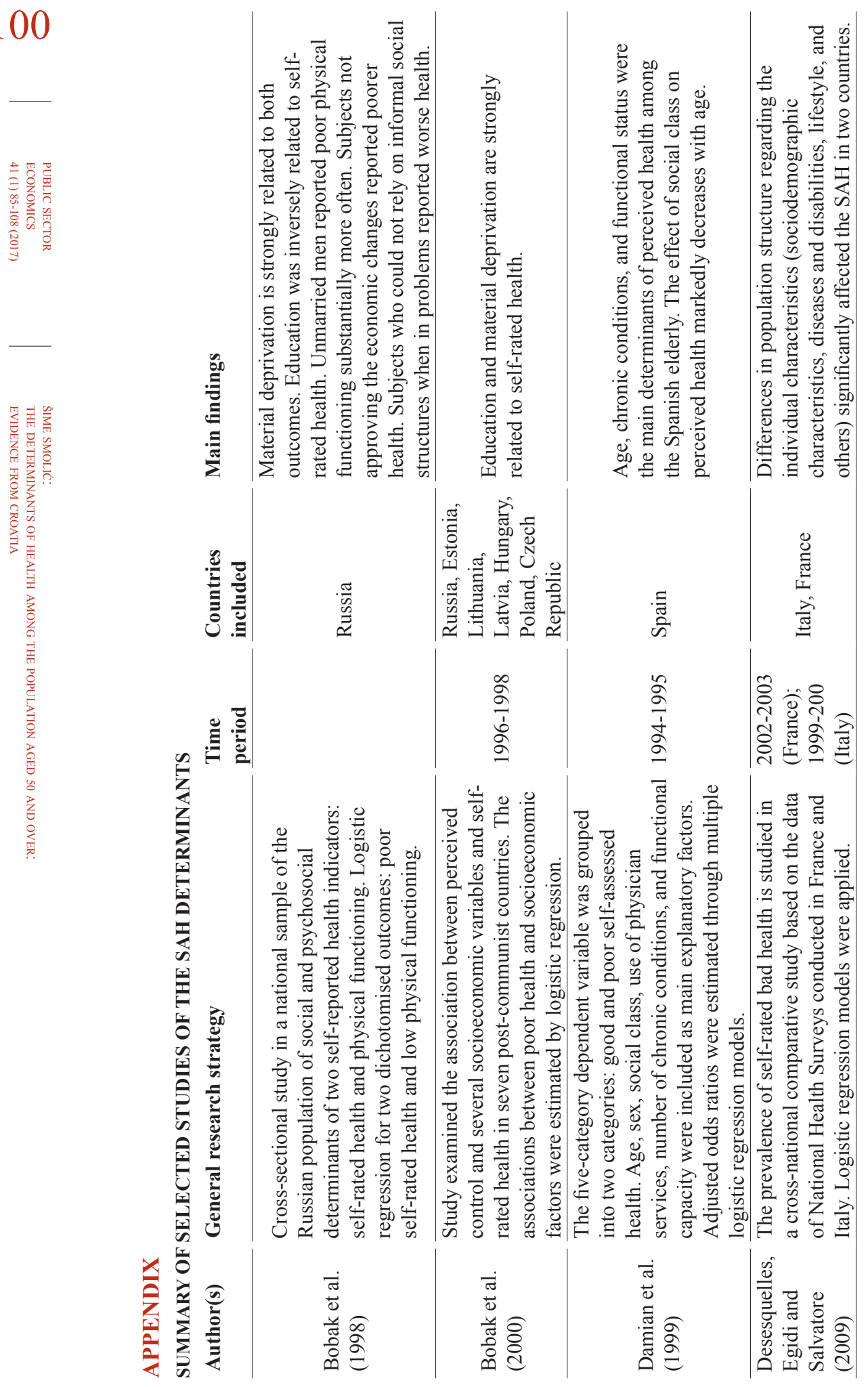


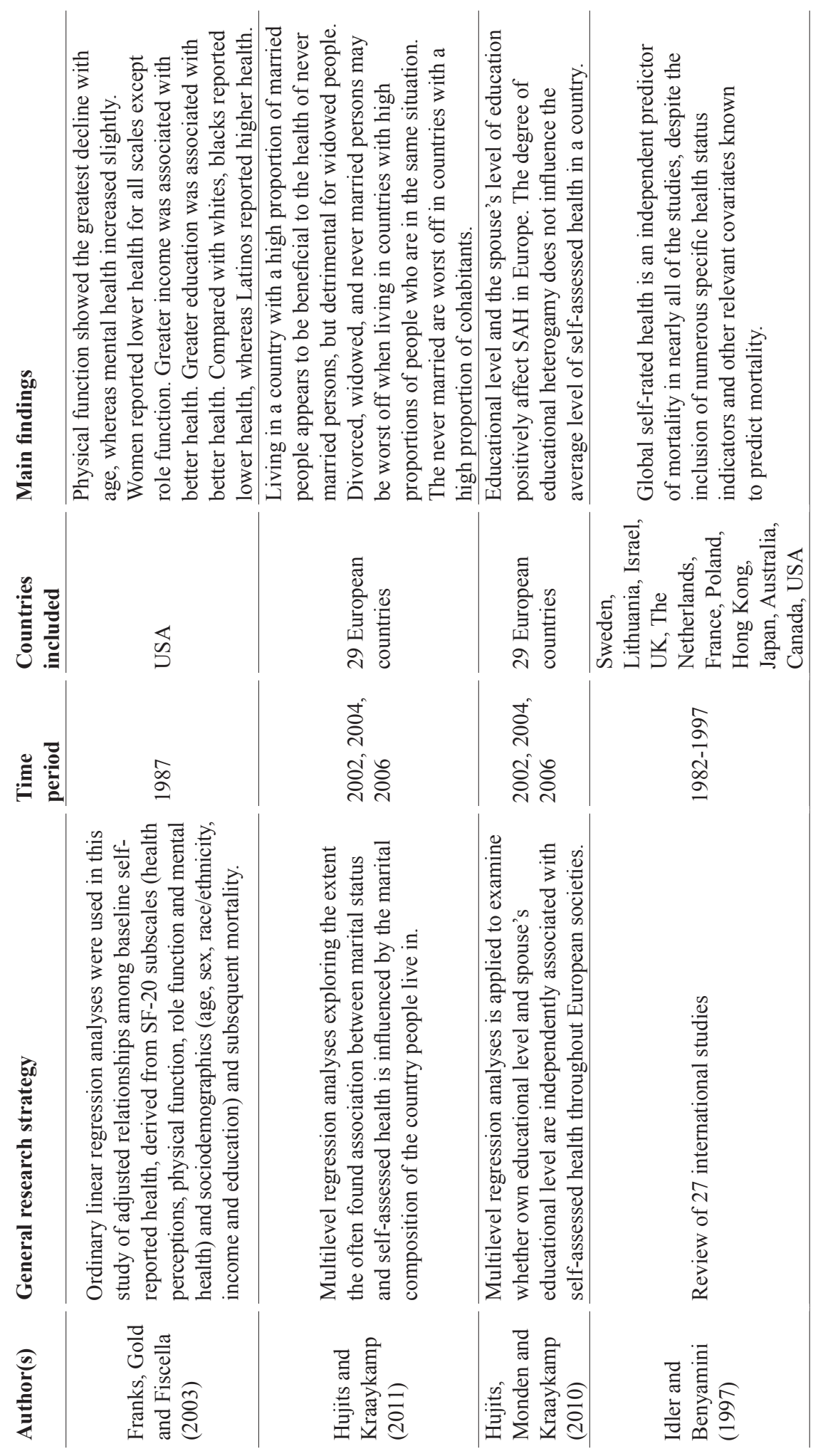

101 
102
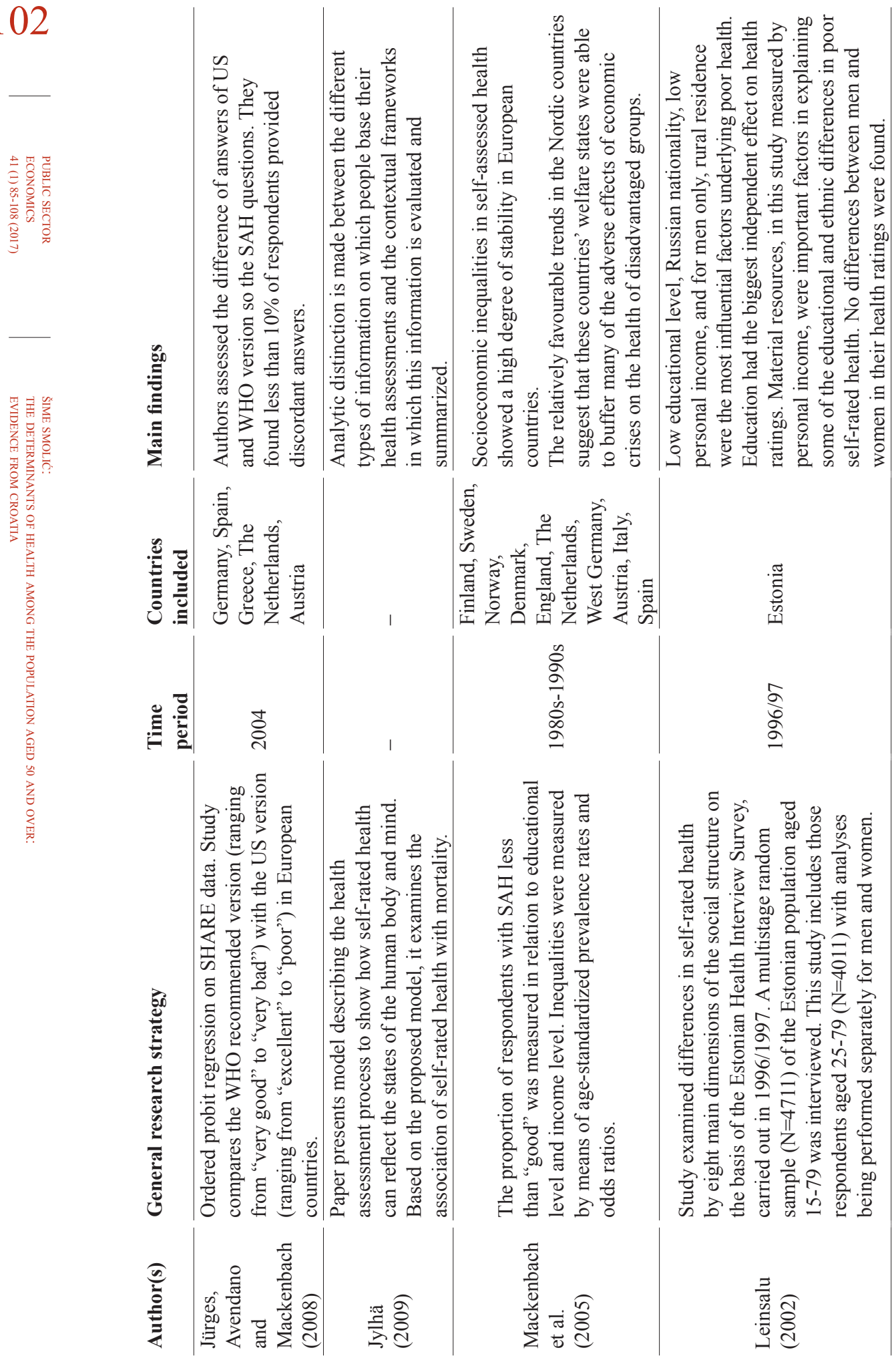


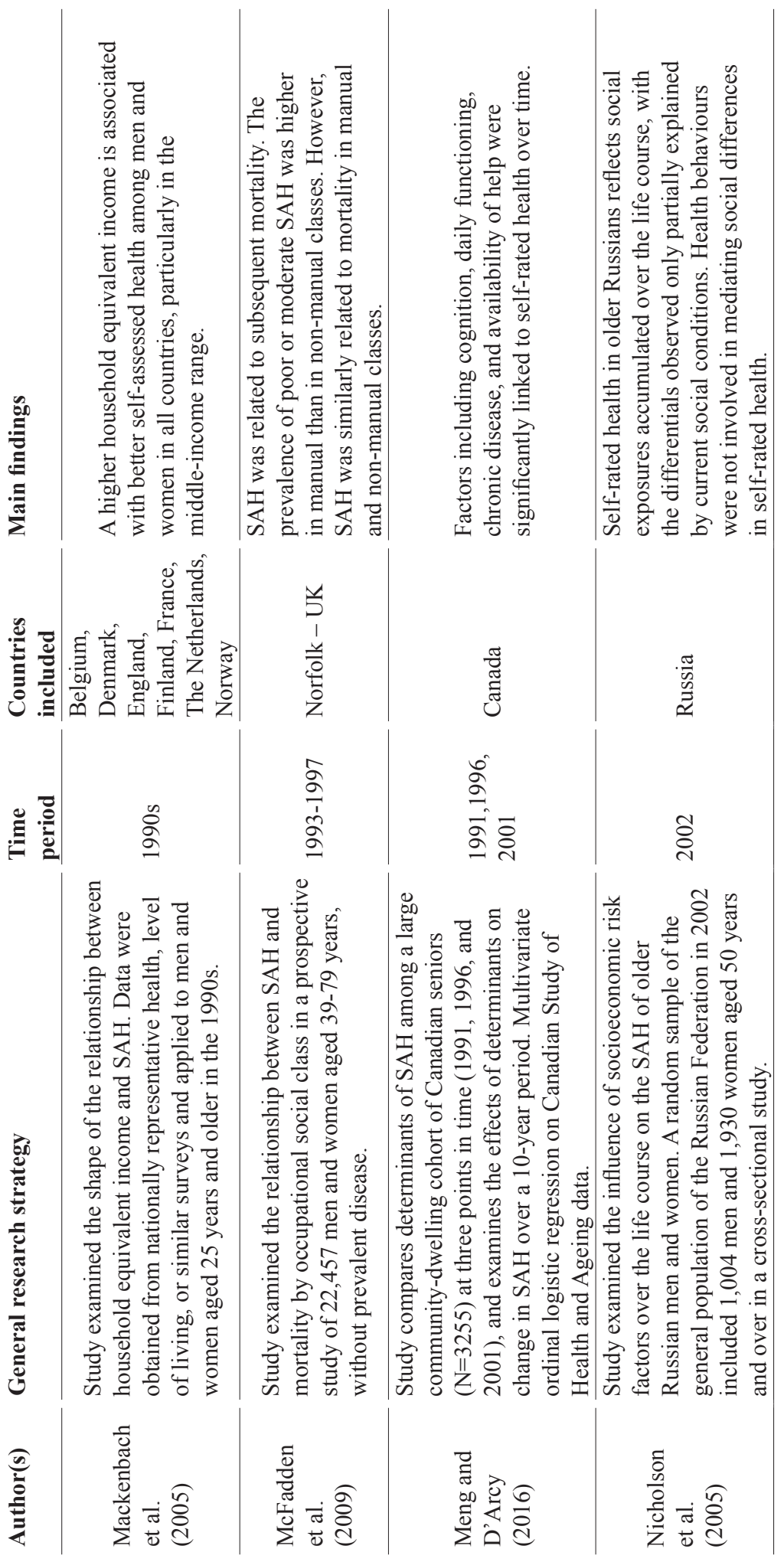

103
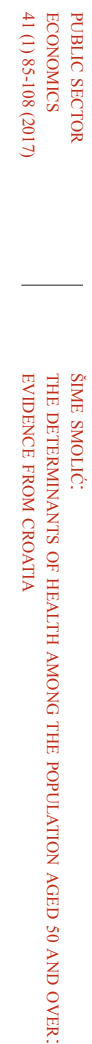
104
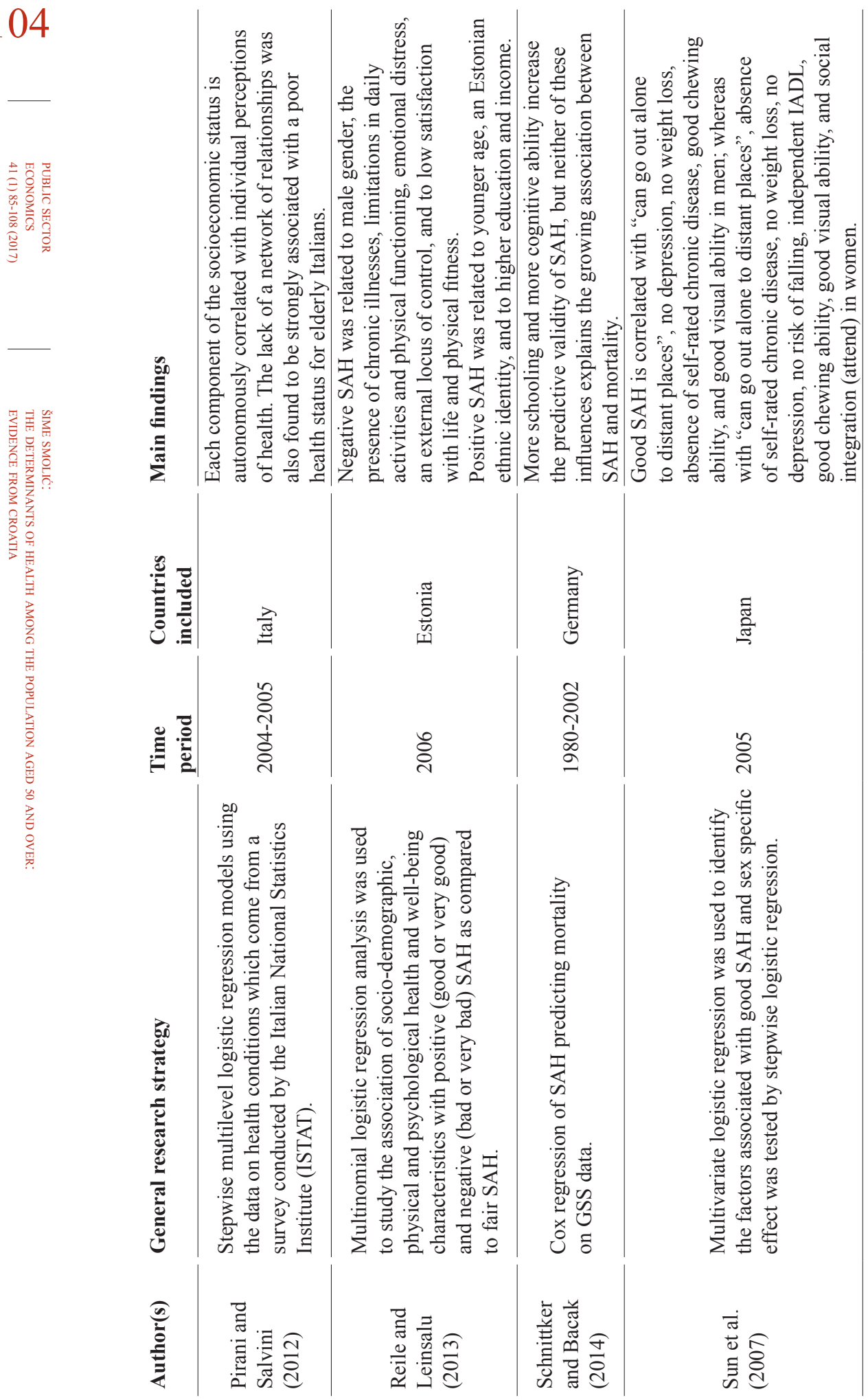


\section{REFERENCES}

1. Adler, N. E. and Newman, K. 2002. Socioeconomic Disparities in Health: Pathways and Policies. Health Affairs, 21(2), pp. 60-76. doi: 10.1377/hlthaff. 21.2.60

2. Agresti, A., 2002. Categorical Data Analysis. Hoboken, New Jersey: John Wiley \& Sons, Inc. doi: 10.1002/0471249688

3. Bailis, D. S., Segall, A. and Chipperfield, J. G., 2003. Two views of self-rated general health status. Social Science \& Medicine, 56(2), pp. 203-217. doi: 10.1016/S0277-9536(02)00020-5

4. Beam Dowd, J. and Zajacova, A., 2007. Does the predictive power of selfrated health for subsequent mortality risk vary by socioeconomic status in the US? International Journal of Epidemiology, 36(6), pp. 1214-1221. doi: 10.1093/ije/dym 214

5. Benyamini, Y. [et al.], 2003. Gender differences in the self-rated health-mortality association: is it poor self-rated health that predicts mortality or excellent self-rated health that predicts survival? Gerontologist, 43(3), pp. 396-405. doi: 10.1093/geront/43.3.396

6. Benyamini, Y., Leventhal, E. A. and Leventhal, H., 2000. Gender differences in processing information for making self-assessments of health. Psychosomatic Medicine, 62(3), pp. 354-364. doi: 10.1097/00006842-200005000-00009

7. Bobak, M. [et al.], 1998. Socioeconomic factors, perceived control and selfreported health in Russia. A cross-sectional survey. Social Science \& Medicine, 47(2), pp. 269-279. doi: 10.1016/S0277-9536(98)00095-1

8. Bobak, M. [et al.], 2000. Socioeconomic factors, material inequalities, and perceived control in self-rated health: cross-sectional data from seven postcommunist countries. Social Science \& Medicine, 51(9), pp. 1343-1350. doi: 10.1016/S0277-9536(00)00096-4

9. Bodenheimer, T., 2005. High and Rising Health Care Costs. Part 1: Seeking an Explanation. Annals of Internal Medicine, 142(10), pp. 847-854. doi: 10.7326/0003-4819-142-10-200505170-00010

10. Börsch-Supan, A. [et al.], 2013. Data Resource Profile: The Survey of Health, Ageing and Retirement in Europe (SHARE). International Journal of Epidemiology, 42(4), pp. 992-1001. doi: 10.1093/ije/dyt088

11. Čipin, I. and Smolić, Š., 2013a. Socio-Economic Determinants of Health in Croatia: Insights from Four Cross-Sectional Surveys. Croatian Economic Survey, 15(1), pp. 25-60.

12. Čipin, I. and Smolić, Š., 2013b. The Economics of Ageing in Croatia - Research Results and Findings [online]. <Available at: http://web.efzg.hr/dok/ $\mathrm{MGR} /$ ssmolic//estarenja/brosura_eng_preview_03-12-2014.pdf $>$.

13. CNIPH, 2016. Croatian National Institute of Public Health. Croatian Health Service Yearbook 2015. (In Croatian) [online]. Available at: $<$ http://www.hzjz. $\mathrm{hr} /$ wpcontent/uploads/2016/05/Ljetopis_2015.pdf $>$.

14. Crossley, F. T. and Kennedy, S., 2002. The reliability of self-assessed health status. Journal of Health Economics, 21(4), pp. 643-658. doi: 10.1016/S01676296(02)00007-3 
15. Damian, J. [et al.], 1999. Determinants of self-assessed health among Spanish older people living at home. Journal of epidemiology and community health, 53(7), pp. 412-6. doi: 10.1136/jech.53.7.412

16. Desesquelles, A. F., Egidi, V. and Salvatore, M., 2009. Why do Italian people rate their health worse than French people do? An exploration of cross-country differentials of self-rated health. Social Science \& Medicine, 68(6), pp. 11241128. doi: 10.1016/j.socscimed.2008.12.037

17. Dominick, K. L. [et al.], 2002. Relationship of health-related quality of life to health care utilization and mortality among older adults. Aging clinical and experimental research, 14(6), pp. 499-508. doi: 10.1007/BF03327351

18. Dormont, B., Grignon, M. and Huber, H., 2006. Health expenditure growth: reassessing the threat of ageing. Health Economics, 15(9), pp. 947-963. doi: $10.1002 /$ hec. 1165

19. Džakula, A. [et al.], 2006. Croatia: Health system review. Health Systems in Transition, 2014, 16(3): 1-162.

20. Eurostat, 2016a. Eurostat Database. Self-perceived health by sex, age and income quintile (update 21 July 2016) [online]. Available at: <http://appsso. eurostat.ec.europa.eu/nui/show.do?dataset=hlth_silc_10.>.

21. Eurostat, 2016b. Eurostat Database. Self-perceived long-standing limitations in usual activities due to health problem by sex, age and income quintile (update 21 November 2016) [online]. Available at: <http://appsso.eurostat. ec.europa.eu/nui/show.do?dataset=hlth_silc_12.>.

22. Ferraro, K. F. and Kelley-Moore, J. A., 2001. Self-Rated Health and Mortality Among Black and White Adults: Examining the Dynamic Evaluation Thesis. Journal of Gerontology: SOCIAL SCIENCES, 56B (4), pp.195-205.

23. Follette, G. and Sheiner, L., 2005. The sustainability of health spending growth. National Tax Journal, 58(3), pp. 391-408. doi: 10.17310/ntj.2005.3.06

24. Franks, P., Gold, M. R. and Fiscella, K., 2003. Sociodemographics, self-rated health, and mortality in the US. Social Science \& Medicine, 56(12), pp. 25052514. doi: 10.1016/S0277-9536(02)00281-2

25. Galić, Z., Maslić Seršić, D. and Šverko, B. 2006. Financial circumstances and health of unemployed persons in Croatia: does financial deprivation lead to poorer health. Revija za socijalnu politiku, 13(3-4), pp. 257-269.

26. Giatti, L., Sandhi, M. B. and Cibele, C. C., 2010. Unemployment and selfrated health: Neighborhood influence. Social Science \& Medicine, 71(4), pp. 815-821. doi: 10.1016/j.socscimed.2010.05.021

27. Grossman, M., 1972. On the Concept of Health Capital and the Demand for Health. Journal of Political Economy, 80(2), pp. 223-255. doi: 10.1086/259880

28. Harper, S., 2006. Addressing the implications of global ageing. Journal of Population Research, 23(2), pp. 205-223. doi: 10.1007/BF03031816

29. Huijts, T. and Kraaykamp, G., 2011. Marital status, nation marital status composition, and self-assessed health. A multilevel test of four hypotheses in 29 European countries. European Societies, 13(2), pp. 279-305.

30. Huijts, T., Monden, C. W. S. and Kraaykamp, G., 2010. Education, Educational Heterogamy, and Self-Assessed Health in Europe: A Multilevel Study of Spousal Effects in 29 European Countries. European Sociological Review, 26(3), pp. 261-276. doi: 10.1093/esr/jcp019 
31. Idler, E. L. and Angel, R. J., 1990. Self-Rated Health and Mortality in the NHANES-1 Epidemiologic Follow-up Study. American Journal of Public Health, 72(8), pp. 446-452. doi: 10.2105/AJPH.80.4.446

32. Idler, E. L. and Benyamini,Y. 1997. Self-rated health and mortality: a review of twenty-seven community studies. Journal of Health and Social Behavior, 38(1), pp. 21-37. doi: 10.2307/2955359

33. Idler, E. L. and Kasl, S., 1991. Health perceptions and survival: do global evaluations of health status really predict mortality? Journal of Gerontology, 46(2), pp. 55-65. doi: 10.1093/geronj/46.2.S55

34. Jürges, H., Avendano, M. and Mackenbach, J. P., 2008. Are different measures of self-rated health comparable? An assessment in five European countries. European Journal of Epidemiology, 23(12), pp. 773-781. doi: 10.1007/s10654-008-9287-6

35. Jylhä, M., 2009. What is a self-rated health and why does it predict mortality? Towards an unified conceptual model. Social Science \& Medicine, 69(3), pp. 307-316. doi: 10.1016/j.socscimed.2009.05.013

36. Kaplan, G. A. [et al.], 1996. Perceived health status and morbidity and mortality: evidence from the Kuopio ischaemic heart disease risk factor study. International Journal of Epidemiology, 25(2), pp. 259-65. doi: 10.1093/ije/25.2.259

37. Kaplan, G. A. and Camacho T., 1983. Perceived health and mortality: a nineyear follow-up of the human population laboratory cohort. American Journal of Epidemiology, 117(3), pp. 293-304.

38. Leinsalu, M., 2002. Social variation in self-rated health in Estonia: a crosssectional study. Social Science \& Medicine, 55(5), pp. 847-861. doi: 10.1016/ S0277-9536(01)00221-0

39. Lima-Costa, M. F. [et al.], 2012. Socioeconomic inequalities in health in older adults in Brazil and England. American Journal of Public Health, 102(8), pp. 1535-1541. doi: 10.2105/AJPH.2012.300765

40. Lindeboom, M. and van Doorslaer, E., 2004. Cut-point shift and index shift in self-reported health. Journal of Health Economics, 23(6), pp. 1083-1099. doi: 10.1016/j.jhealeco.2004.01.002

41. Liu, I. and Agresti, A., 2005. The analysis of ordered categorical data: An overview and a survey of recent developments. Spanish Statistical Journal, TEST, 14(1) pp. 1-73. doi: 10.1007/BF02595397

42. Long, J. S. and Freese, J., 2006. Regression Models for Categorical and Limited Dependent Variables Using Stata. College Station, Texas: Stata Press.

43. Mackenbach, J. P. [et al.], 1997. Socioeconomic inequalities in morbidity and mortality in Western Europe. The EU working group on socioeconomic inequalities in health. The Lancet, 349(9066), pp. 1655-1659. doi: 10.1016/ S0140-6736(96)07226-1

44. Mackenbach, J. P. [et al.], 2005. The shape of the relationship between income and self-assessed health: an international study. International Journal of Epidemiology, 34 (2), pp. 286-293. doi: 10.1093/ije/dyh338

45. Mackenbach, J. P., 2006. Health Inequalities: Europe in Profile. London: Department of Health.

46. McDonough, P. and Walters, V., 2001. Gender and health: reassessing patterns and explanations. Social Science and Medicine, 52(4), pp. 547-559. doi: 10.1016/S0277-9536(00)00159-3 
47. McFadden, E. [et al.], 2009. Does the association between self-rated health and mortality vary by social class? Social Science \& Medicine, 68(2), pp. 275280. doi: 10.1016/j.socscimed.2008.10.012

48. Meng, X. and D’Arcy, C., 2016. Determinants of Self-Rated Health Among Canadian Seniors Over Time: A Longitudinal Population-Based Study. Social Indicators Research, 126(3), pp. 1343-1353. doi: 10.1007/s11205-015-0941-6

49. Mossey, J. M. and Shapiro, E., 1982. Self-rated health: A predictor of mortality among the elderly. American Journal of Public Health, 72(8), pp. 800-808. doi: 10.2105/AJPH.72.8.800

50. Newhouse, J., 1992. Medical care costs: how much welfare loss? Journal of Economic Perspectives, 6(3), pp. 3-21. doi: 10.1257/jep.6.3.3

51. Nicholson, A. [et al.], 2005. Socio-economic influences on self-rated health in Russian men and women - a life course approach. Social Science \& Medicine, 61(11), pp. 2345-2354. doi: 10.1016/j.socscimed.2005.07.034

52. Okunade, A. A. and Murthy, V. N., 2002. Technology as a "major driver" of health care costs: a cointegration analysis of the Newhouse conjecture. Journal of Health Economics, 21(1), pp. 147-159. doi: 10.1016/S0167-6296(01)00122-9

53. Peersman, W. [et al.], 2012. Gender, educational and age differences in meanings that underlie global self-rated health. International Journal of Public Health, 57(3), pp. 513-523. doi: 10.1007/s00038-011-0320-2

54. Priani, E. and Salvini, S., 2012. Socioeconomic Inequalities and Self-Rated Health: A Multilevel Study of Italian Elderly. Population Research and Policy Review, 31(1), pp. 97-117. doi: 10.1007/s11113-011-9219-0

55. Reile, R. and Leinsalu, M., 2013. Differentiating positive and negative selfrated health: results from a cross-sectional study in Estonia. International Journal of Public Health, 58(4), pp. 555-564. doi: 10.1007/s00038-013-0445-6

56. Schnittker, J. and Bacak, V., 2014. The Increasing Predictive Validity of SelfRated Health. PLoS ONE, 9(1): e84933. doi: 10.1371/journal.pone.0084933

57. Stuckler, D., Basu, S. and McKee, M., 2013. Public Health in Europe: Power, Politics, and Where Next? Public Health Reviews, 32(1), pp. 213-242.

58. Sun, W. [et al.], 2007. Factors associated with good self-rated health of nondisabled elderly living alone in Japan: a cross-sectional study. BMC Public Health, 7(297), pp. 1-9. doi: 10.1186/1471-2458-7-297

59. Šućur, Z. and Zrinšćak, S., 2007. Differences that Hurt: Self-perceived Health Inequalities in Croatia and European Union. Croatian Medical Journal, 48(5), pp. 653-666.

60. Vončina, L. [et al.], 2006. Croatia: Health system review. Health Systems in Transition, 8(7), pp. 1-108. Available at: <http://www.euro.who.int/_data/assets/pdf_file/0020/252533/HiT-Croatia.pdf?ua=1>.

61. WHO, 2016a. European Health for All Database (version July 2016) [online]. Available at: $<$ http://data.euro.who.int/hfadb/>.

62. WHO, 2016b. Global Health Observatory (GHO) data [online]. Available at: $<$ http://www.who.int/gho/publications/world_health_statistics/2016/dashboard/ en $/>$.

63. Zajacova, A. and Beam Dowd, J., 2011. Reliability of Self-rated Health in US Adults. American Journal of Epidemiology, 174(8), pp. 977-83. doi: 10.1093/ aje/kwr204 